\title{
The York Digital Journals Project: Strategies for Institutional Open Journal Systems Implementations
}

\section{Andrea Kosavic}

\begin{abstract}
Embarking on a universitywide journal-hosting initiative can be a resourceintensive undertaking. Providing such a service, however, can be equally rewarding, as it positions the library as both partner and colleague in the publishing process. This paper discusses ideas and strategies for institutional journal hosting gleaned over two years by the York Digital Journals Project. Suggestions for startup including policy considerations and service models are discussed. Ideas for advertising and networking are explored as well as the question of project sustainability.
\end{abstract}

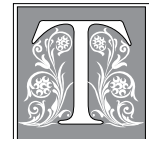

here is abundant evidence that research articles openly accessible online benefit from increased visibility and use, leading to increased citation over closedaccess journals. ${ }^{1}$ But how to do so outside of traditional journal avenues has been a barrier to researchers who wish to make their findings available online free of charge. ${ }^{2}$ Willinsky's Open Journal Systems (OJS), which is a free, open-source journal publishing software utility, ${ }^{3}$ has been used to address these needs. At York University, our experience with OJS thus far is indicative of the great potential that lies within the system and, with it, potential new models of scholarly communication. This article will provide an introduction to OJS and the Synergies project as a means of expounding upon new directions in libraries and publishing. A review of some of the literature surrounding open access and scholarly communication follows as a means of introduction.

\section{Literature Review}

The subject of OJS and its implementation in academic library environments is a fairly new one, as the major developments in this field stretch back barely a decade. Much work remains to be done to fully gauge the effect that OJS systems will have on scholarly communication, library budgets, and the financial viability of the OJS titles themselves. The main point of departure for discussion of this topic, at least in the Canadian context, revolves around John Willinsky and the Public Knowledge Project (PKP) at the University of British Columbia. ${ }^{4}$ Willinsky traces the development of OJS as arising from the PKP, whose team of designers and developers created the OJS system, one of several open journal software packages that currently exist.

Andrea Kosavic is Digital Initiatives Librarian in Scott Library at York University; e-mail: akosavic@yorku. ca. The author gratefully acknowledges Erik Brea, Melissa Troemel, Stephanie Walker and Rob van der Bliek for their contributions. (C) Andrea Kosavic 
Willinsky outlines the history of the OJS system, detailing the various iterations of the software that his team developed, as well as the extensive research into design, reading habits, needs of scholars, editorial flow, and financial costs of online journal hosting that were all considerations when designing and implementing the software. It is the attention paid to these considerations that has helped gain acceptance of the system, thus contributing to its popularity and growth.

Complementary to Willinsky's account is that of Rowland Lorimer's. ${ }^{5}$ His work is particularly important as it traces the history of the Synergies project that we at York University Libraries (YUL) are a part of. His account is extensive, as he outlines what he calls the "dysfunctional" journal publishing environment that is causing a shift in thinking about how best to facilitate scholarly communication. He believes that the traditional model of subscriberbased journals and scholarly publishing is inadequate in the face of rapid technological change and the desire of scholars in a wired environment to make as much of their research as openly accessible as possible. Beginning with a conference at Simon Fraser in 1997 (Scholarly Communication in the Next Millennium: Canada's Policy Conference), with a follow-up conference in 2002 sponsored by the Canadian Association of Research Libraries (CARL), key principles on open access and ideas on alternatives to publisher-driven journal models emerged and formed the basis of initiatives such as Synergies.

The Synergies project is the end product of these previous discussions and has been made possible in collaboration with Canadian Association of Research Libraries (CARL) along with grants from the Social Sciences and Humanities Research Council of Canada (SSHRC). Lorimer expounds upon the economics of OJS journals and compares costs between them and traditional print and publisher-driven pricing. He finds that moving to an OJS platform, along with what he calls a "self-sustaining, cost-recovery service" administered by his library at Simon Fraser University, leads to a much more sustainable, effective, and equitable means of fostering open scholarly communication. It is Lorimer's matter-of-fact approach in relating the implementation of OJS at his institution that acts as a model for this paper.

Another useful work in this regard is that by Owen and Stranack, ${ }^{6}$ which acts as a complement to Willinsky's account. We share their observations of OJS acting as a means to potentially reduce publishing costs and as a way for libraries to become true partners in the scholarly publishing process. Our observations at York are thus very similar to those of Owen and Stranack at Simon Fraser.

A consensus seems to be emerging whereby many are dissatisfied with the traditional, publisher-driven costs of serials prices, and so the issue remains at the forefront of scholarly communication given that those costs have risen so dramatically. Observers such as Tenopir and King, ${ }^{7}$ Lorimer ${ }^{8}$ Budd, ${ }^{9}$ and $\mathrm{McCabe}{ }^{10}$ have also discussed this issue. As the cost of journals increases parallel with developments in digital technologies (hyperlinking, archival capability), many are looking to online resources as the future of scholarly communication and as a means of reducing costs and increasing scholarly visibility.

With regard to scholarly communication, observers such as Fisher ${ }^{11}$ believe that the future lies with online, open access, free of the traditional constraints imposed by expensive journal publisher contracts. Institutions such as universities are the forefront of this shift, and the literature on the topic includes examples of on-the-ground librarians reporting their findings moving toward an OJS platform. Case and John ${ }^{12}$ at the University of Chicago library, for example, found that their shift of the journal Behavior and Social Issues to OJS led to a significant increase in hits for the journal, nearly tripling from 6,000 per month to about 18,000 . While only one example, it lends support to our efforts at YUL of using OJS and open 
access to maximize visibility and accessibility of the work of the scholars we support at York University.

Different models of open-access publishing are emerging, and the study conducted by Walters ${ }^{13}$ compared them along with current subscription-based models and found variations in costs depending on the model. He concludes that open-access pricing can vary substantially from one university to the next and that, for smaller universities, openaccess models are cheaper than under a conventional pricing model. However, his research suggests that the success of open access may depend upon the willingness of the largest research universities to bear the lion's share of the costs toward its implementation. This is because it is they who will bear the highest burden in the author-pays model, as it is those universities that are responsible for the largest amount of research given that, in his words, "most colleges and universities... can be regarded chiefly as consumers rather than producers of research." Potential economic disparities such as these may act as significant barriers to full adoption of open-access models of scholarly publishing, and one hopes that more research will be done in this area as OJS systems are implemented on a broader scale. Clearly, costs will continue to be an important, if not the most important, criteria by which universities will decide whether to proceed with OJS and similar systems.

Observers such as Chang ${ }^{14}$ and Crow and Goldstein ${ }^{15}$ remind us that specific models of open access may have slightly different features, and emphasize different elements over others, but are all implemented in the cause of reducing costs and increasing the availability of scholars' work. Crow and Goldstein's work, moreover, provides an excellent discussion of how to create an openaccess journal and outlines the various streams of revenue (in addition to supporting elements such as web hosting and other technical requirements) that are necessary for the journal to be sustainable. These are all issues that we have encountered, and will continue to wrestle with, as the OJS/Synergies project continues its evolution at York.

\section{Open Journal Systems at York University Libraries}

The adoption by York of OJS took place in a context where universities are beginning to see themselves as a central part of the scholarly publishing process. Indeed, recent results from the Association of Research Libraries' (ARL) study of research library publishing services revealed that 64 percent of ARL institutions surveyed were either planning or actively involved in offering publishing services. ${ }^{16}$ Of those, the most popular service offered by the active institutions was the publishing of journals, in which 88 percent were engaged, when surveyed in late $2007 .{ }^{17}$

York University Libraries decided to offer a library publishing service in late 2006. By launching York Digital Journals (YDJ), the libraries hoped to promote the availability and accessibility of scholarly output produced by the York University community and its affiliates. Open Journal Systems was chosen as the software to support the publishing service due to its large user community and its endorsement by the Synergies initiative.

The Synergies initiative is a collaborative project among 21 Canadian universities. Its goal is to promote, preserve, and distribute Canadian Social Science and Humanities research by bringing the research to the Web through the use of several platforms: Open Journal Systems, Open Conference Systems, DSpace and Érudit. Funded by the Canadian Foundation for Innovation, the Synergies project is creating a portal that will aggregate research collected through the platforms into a portal of Canadian Social Science and Humanities scholarship. (For more information, see: www.synergiescanada. org.)

With the promise of future funding through Synergies, York University 
Libraries invested numerous resources into developing the York Digital Journals project. The potential benefit of YDJ for faculty was recognized at the outset and as a result was supported by the university and senior library administration.

In its early stages, YDJ was fortunate to have multiple layers of support from library and university administration, as well as faculty members, librarian mentors, and library computing services. Additional support was made available in the form of funding for part-time workers who assisted in the implementation of the initiative (and continue to do so). All efforts were made to provide service to the best of our ability and disincentives such as any associated costs (such as hosting fees) and restrictive policies (such as only serving open-access journals) were not applied to the first phase of the project. As a result, community acceptance and uptake of the service was high to the extent that we now currently host 18 journals on our site.

This paper draws upon experiences and lessons learned during the first two years of this ongoing project. These have been distilled into the following list of strategies and recommendations for institutions planning to implement similar programs locally.

\section{Background Research and Preparation}

At York the pilot phase was short due to keen interest from faculty by word of mouth. As a result, many of the suggestions in this section were implemented as the need for them arose. Ideally, the suggestions discussed below should be explored first, as they help to build a solid foundation for future growth.

\section{Establish a Solid Background in Scholarly Publishing}

Experience at York has shown that a number of faculty members are often interested in having a conversation about scholarly publishing developments in general before discussing the technical details of the Open Journal Systems plat- form itself. In many cases, this conversation turns out to be an excellent insight into discipline-related attitudes toward open access. For example, in the social sciences, a strong attachment to print has been observed, which often results in a noticeable hesitance toward adopting open-access models.

A lack of solid understanding of underlying open-access issues has been observed at Cornell University Library, ${ }^{18}$ and we have made similar observations. Some of our informal conversations with faculty reveal misconceptions about open access that present an opportunity to challenge the myths and perceptions that some faculty adhere to. One false impression that we encountered is the belief that only articles that are published in open-access journals can be considered open access. This is not the case, and this misunderstanding of the concept provides a great opportunity to discuss the many flavors of open access as outlined by Willinsky. ${ }^{19}$

For example, a solid backgrounder on open access and associated current developments can be found in Peter Suber's Open Access Overview ${ }^{20}$ and his monthly SPARC Open Access Newsletter. ${ }^{21}$ Both are highly recommended based on the experience of this writer. In addition, to more fully understand the publishing process, David Solomon's recent book Developing Open Access Journals: A Practical Guide ${ }^{22}$ is recommended as an ideal introduction to the many facets of this field. And, as noted above, Crow and Goldstein provide an excellent discussion of the business models to consider upon launching an open-access journal, as well as the role of "interorganizational" partnerships that can be crucial to the success of the endeavor. We found such partnerships very valuable in our experience.

Ongoing engagement of faculty and colleagues in discussion about the publishing process proved to be very useful. At York we found that faculty periodically hosted seminars on campus, geared toward graduate students, that explained the publishing process. We found attend- 
ing these seminars helpful in understanding different perspectives, as they enabled us to more fully understand the publishing needs of our clients.

In addition, for an institution piloting Open Journal Systems, it was very informative to read John Willinsky's The Access Principle to understand the inspiration behind why the software was created. Willinsky discussed the many obstacles that the project was designed to overcome, and we found ourselves drawing upon examples from this book in conversations with faculty.

\section{Form an Early Partnership with Your Local IT Department}

The project initially appeared as though it would not require much hands-on time by our library's computing department. It was thought that an install, regular updates, and nightly data backups would suffice, as our partnership with Synergies would address preservation strategies. This did not turn out to be the case, and it could largely be attributed to the growing scale of the project.

To accommodate our growth, a faster server environment was needed to handle significant increases in site traffic. Our faculty began to ask for added functionality and to request customizations to the software, which resulted in the need for programming time. While the need for customization was anticipated, ${ }^{23}$ we were unable to fulfill all customization requests. All faculty feedback was valuable and presented an opportunity to give back to the Open Journal Systems open source community by sharing suggestions and the code for our customizations.

We were also pleased to discover that the Public Knowledge Project development team (creators of Open Journal Systems) was more than happy to communicate with our IT department, receive our code contributions, talk to us about our experiences with the software, and include our requests in their code development road maps.

\section{Start Small}

The pilot phase provided key insights used to discover our service model boundaries and better understand the benefits and potential limitations of the OJS platform.

We were fortunate to be able to pilot our system with two journals. One was brought in through a colleague's association connection, the other through a liaison librarian connection with a faculty member. This was an important learning experience, as it gave us our first glimpse into discipline-specific faculty attitudes toward open access.

These early conversations helped to identify areas where we needed to conduct more research and anticipate future questions from faculty. Many of the questions required referencing OJS manuals, scouring the Public Knowledge Project message boards, or researching scholarly sources to be able to follow up. While time consuming, the number of queries was manageable as we were still in the pilot phase.

\section{Policy Development}

It is our hope that the lessons learned from piloting journals may provide a useful foundation for the future scope of your OJS project. We recommend that some basic terms of use and service boundaries be established before seeking to host additional journals.

\section{Clearly Articulate Service Model Boundaries}

Articulating service model boundaries is a crucial step toward a manageable workflow. This ensures that you and your staff do not take on more than the team can handle. The pilot phase helps to quickly identify which services your institution is outfitted and staffed to provide.

Our initial goal at York was to fully train journal staff to be self-sufficient in the use of Open Journal Systems software, so that our intervention would be minimal. This was, in the case of most journals, unrealistic.

Several factors complicated the scenario, the most serious being the turnover 
of volunteers and student help that keep many journals afloat. In the case of some journals, just as students were becoming fully proficient with the system, they graduated or found a job elsewhere. As a result, some journals preferred to maintain their old submission workflow and asked us to upload current issues as they became available. Uploading required minimum effort on our behalf, and we were happy to provide this service.

We decided not to offer layout or copyediting services. While some feebased publishing service models exist, such as the services offered by the Canadian Centre for Studies in Publishing Press at Simon Fraser University, ${ }^{24}$ it is more common that libraries require authors and editors to deliver edited material. ${ }^{25}$ Journals that were established prior to working with us had previous copyediting arrangements; and, for new journals, we suggested adopting uniform style and content guidelines to minimize layout reformatting. In addition, we encouraged these new journals to seek advice from colleagues for disciplinespecific advice and contacts.

From a design perspective, we had inhouse talent that worked with journals to create a satisfactory online presence. This service was basic in that it did not involve any coding; usually some graphics were added and the cascading style sheets (CSS) were modified accordingly. With respect to the marking up of (X)HTML versions of articles, we decided to provide basic guidance in lieu of a service.

This decision was supported by research presented at the International Conference on Electronic Publishing, where survey results show a decline in popularity of $(X) H T M L .{ }^{26}$ It was found that close to three quarters of the journals surveyed published articles in PDF, whereas between 36.6 percent and 48.8 percent publish in (X)HTML, with one fifth of the total sample making journal articles available in more than one file format. ${ }^{27}$

Another factor in our decision was cost. Approximately half of our journals had significant back files, which would have required years of dedicated part-time student labour to format with the appropriate tags. While we would ideally liked to have provided the full text of journal articles in (X)HTML as well as in PDF format, the declining popularity of $(X)$ HTML coupled with the cost of creating it make this format unfeasible.

\section{Establish Terms of Use}

Faculty's strong interest, coupled with rapid growth in demand, proved to be somewhat challenging from a policy standpoint. Questions such as criteria for journal acceptance and methods for ensuring sustainability began to surface.

We chose not to be restrictive in our criteria for journal acceptance, as library presses tend to publish material that lacks a ready commercial market such as material in the humanities and social sciences. ${ }^{28}$ We brought that mindset to our project and used it to direct our decision making in this area.

This became evident during the process of brainstorming a potential policy that was to govern several publishing issues, including York University's liabilities with respect to hosting the journals, the responsibilities of the journal creators, and York University Libraries' assurances to YDJ users.

We asked ourselves the following questions when drafting our policy:

- Is YDJ a publisher, a dissemination platform, or both?

- Who assumes liability for the content posted to the platform?

- Will we allow access or cost restrictions to be placed on content?

- What are the responsibilities of York Digital Journals to its hosted journals?

- What happens if a journal decides to migrate away from the YDJ platform?

Our brainstorming exercise with York legal counsel resulted in some basic guidelines that included wording identifying YDJ as the platform only and not the publisher for those publications. As an extension, we were not to be held 
accountable for any content posted to the platform by the journals themselves.

As the host of the platform, York itself did not put any access or cost restrictions on the platform. While journals are discouraged from imposing access barriers via embargo or subscriptions, this is at the discretion of the journals themselves.

With respect to providing a reliable service, we included wording with our promise to strive to keep the software upto-date, to provide reliable $24 / 7$ service, and to ensure the persistence and stability of the content. Journals are to be provided with advance written notice in the event of YUL implementing a cost recovery program or the discontinuing of the service, as well as any other measure that may seriously affect the journals themselves.

Finally, in the interest of securing permanent access to research, we included a clause that enabled YDJ to retain the right to archive all deposited data in the event that a journal ceased to use YDJ as a platform.

Our model resembled that of HighWire Press $^{29}$ at Stanford University, where we considered ourselves to be more of a hosting service provider and not a publisher. Our guidelines were consistent with what Harboe-Ree has observed in the case of library presses: library presses differ from academic presses in that they are not separate legal and commercial entities, which make them less accountable and more flexible as they are not bound by strong advisory committees or boards. ${ }^{30}$

\section{Provide Advice Regarding Copyright Transfer Policy}

In addition to providing journal creators some background information about the benefits of open access and possible models that could be adopted, we took the opportunity to discuss the benefits of less restrictive copyright arrangements between authors and the journal. Journal managers and editors were directed to the Creative Commons Web site, and the nuances of gratis and libre ${ }^{31}$ open access were discussed. Excellent less restrictive model agreements have been developed by and are available on the Scholarly Publishing Office Web site of the University of Michigan Library.

While our ability to help journals in this regard was limited as we are unable to provide a legal opinion, our efforts did in some cases influence journal editors to draft more open agreements that included explicit language allowing authors to selfarchive the publisher version of their own work, to reuse and build on their work, and to distribute their work for noncommercial purposes.

\section{Advertising and Networking}

Based on the challenges discussed earlier, it was shown that maintaining the OJS software environment was only part of the picture for a journal hosting program. Equally vital to the project's success was the ability to create excitement about the software itself and stimulate discussion highlighting the many strengths and benefits of hosting a journal with the libraries in an open source software product.

\section{Tap into Administrative Support as well as Local Connections and Knowledge}

We were very fortunate to benefit from the active support of our university librarian, who promoted the project at the senior library administrative level with great enthusiasm. This active promotion opened doors for presentations to faculty committees and thus allowed us to be introduced to deans and directors of research initiatives. As a result, more invitations to speak at other meetings followed. Overall, several valuable new relationships were forged and maintained that have helped to expand the program.

In addition, the project benefited from the scholarly publishing knowledge of two senior colleagues who took a special interest in the project. These colleagues elevated the status of the project to a team effort and shared their experiences of publishing through the OJS platform 
with faculty. This was very helpful as they decoded the nuances of faculty questions using a scholarly communications subtext. Their support was instrumental to the rapid uptake of the software by faculty.

Ensuring that liaison librarians and reference librarians were aware of the project was also an important step. Arranging a block of time in a meeting to promote awareness of our initiative helped to form a network of referrals and allowed our colleagues to route any associated questions to project members directly. This model of referrals by liaison librarians continues to be an important advertising method for YDJ and other York digital initiatives.

\section{Consider a Scholarly Communications Program}

We were given an excellent opportunity to discuss open access concepts with faculty members and graduate students through our work with various journals, and we observed varying degrees of comprehension, adoption, and acceptance of open access among faculty.

It became clear that it was important to frame our York Digital Journals initiative within a scholarly communications context. Attending the ARL Scholarly Communications Institute in 2007 was an excellent learning experience, as it helped us to develop strategies to move the project forward and to capitalize on faculty interest in online publishing. This led to conversations about perceptions of open access by their various disciplines. We formed a Scholarly Communications Committee, which maintains a Web site, hosts speaker events on campus, and speaks to faculty and graduate students about the issues.

Consequently, a very useful symbiosis between the two initiatives was formed, where events hosted by the Scholarly Communications Committee were ideal for spreading the word about how York could help faculty move forward in their adoption of open access models. Simi- larly, interest in York Digital Journals and our institutional repository, YorkSpace, enabled us to have discussions about open access. Opinions collected through these discussions helped the Scholarly Communications Committee plan their events around issues with the highest degree of relevance to faculty and graduate students.

\section{Use Campus Advertising to Your Advantage} In addition to the indirect advertising via the Scholarly Communications committee, the YDJ project used several established advertising methods to announce the project on campus.

York University has a daily campus e-newsletter called YFile. The editors of the e-newsletter were contacted, and several articles featuring the project were published. The first article introduced the project and its pilot journals, while others featured new journals launched through the York Digital Journals project as they came on board.

This generated multiple calls of interest and an outcome of several new hosted journals at York. In addition, the library publishes a quarterly newsletter for faculty, where the YDJ project was featured alongside library digital initiatives.

To support these publications, we created an information site that introduces OJS, discusses the library's role in the project, introduces related concepts such as open access and author rights and provides a FAQ for potential users. Links to related presentations archived in the institutional repository were (and are) posted on the YDJ project Web site. We were pleasantly surprised to see that faculty turned to these presentations first, sometimes even bringing printouts of the PowerPoint slides themselves to informational meetings.

By far, however, our most effective advertising was word of mouth. The managers of the journals continued to refer us to their colleagues. Subsequently, more faculty and graduate students worked with us on the YDJ project than we had thought possible at the outset. 


\section{Make Your Project Known to Key IT and Research Contacts on Campus}

The legwork by our university librarian to secure agenda time with campus committees proved to be very beneficial.

Due to the broad representation of the committees, multiple campus services became aware of our project. Major IT service providers on campus, including our Faculty Support Centre and Central Networking Services, were immediately interested in our work. We were thus able to meet and exchange information about the services that we offered. Through these meetings, we learned that the Faculty Support Centre had in fact previously tested an installation of Open Journal Systems but did not take the project further due to lack of available resources.

In addition to meeting with York's Central Networking Services, York's panel of research officers invited the YDJ team to present the project at a general meeting. The presentation generated many questions and expressions of interest, and research officers were able to forward related queries from faculty to the YDJ team, thereby improving the exchange of information among multiple stakeholders.

\section{Project Development and Sustainability \\ Collect Comprehensive Statistics}

We found that collection and dissemination of statistics was and continues to be an important component of the project's success. Detailed statistics help track journal workflow and gauge increases in readership and popularity; in addition, they are often required for grant applications.

Readership statistics are very important to journals at York, as approximately half of the YDJ hosted journals applied for funding through the Social Science and Humanities Research Council (SSHRC) Aid to Journals program in the summer of 2008. SSHRC requested readership data for electronic journals by way of detailed Web usage reports, which should ideally have included: the number of unique visitors, the geographic locations of visitors, the number and duration of visits, the number of hits and pages accessed, and the number of RSS feeds.

Unfortunately, not all of this data was automatically collected by OJS or its associated plug-ins. Open Journal Systems tracks detailed journal workflow tracking statistics, abstract views, as well as PDF and HTML (full-text "galley") views in its native database. The full-text galley views were collected by journals, and totals were displayed by month using a COUNTER plug-in. None of the abovementioned statistics were of interest to SSHRC for the purposes of the 2008 Aid to Journals grant.

With recent releases of OJS, the ability to integrate Google Analytics collection at the journal level has improved the variety of statistics that are collected, including unique visitors and their geographic locations, number of visits, and number of pages accessed.

To be able to provide a full spectrum of readership data, however, the installation of a server log analyzer is highly recommended. The YDJ platform is now using AWStats, which, while available without cost on the Web, was found to be somewhat time consuming for our IT department to configure due to our multiple journal hosting situation.

Setting up a server log analyzer infrastructure as part of the piloting phase of OJS installation is highly recommended from the outset to ensure adequate statistics capture. Failing to do so may result in a gap in statistics capture, as servers need to be configured to retain server logs so as not to lose data. If you have an installation of OJS but do not have the time or resources to configure a server log analyzer, talk to your IT department to ensure that the server logs for your installation of OJS are retained and archived for future analysis.

\section{Consider Sustainability Threats and Opportunities}

Karla Hahn's article is again useful to reference with respect to sustainability. 
Hahn's research shows that libraries are well aware that they will have to sustain their scholarly publishing programs themselves with operating budgets. ${ }^{32}$ This has also been our observation, due to the challenges many of our journals continue to have in sustaining themselves.

This challenge is echoed by HarboeRee, ${ }^{33}$ where she identifies that a major difference between libraries and traditional publishers is that, where publishers are strong in establishing and managing distribution and access channels, the libraries tend to be weak in the area of implementing cost recovery models.

York University Libraries is essentially funding the YDJ journals in kind by donating a hosting environment and staff training for the immediate future. At a later point of reassessment, a fee may be required and these journals may need to seek out additional funding for online hosting.

The question of whether to charge for journal hosting is a complicated one. When looking at the Canadian landscape, the hosting of electronic journals is becoming widely adopted by universities. Some, like the Simon Fraser University Library, charge a nominal per annum fee for journal hosting and support, with additional charges for customizations. Consortia such as Érudit also charge a hosting fee, which can be offset by government grants.

From the YDJ perspective, the charging of a hosting fee would be an obstacle to many of the journals. Funding for YDJ journals is largely in kind, where the time devoted by the editors and peer reviewers, along with the administrative overhead, are donated by faculty and graduate students. For those journals that successfully apply for SSHRC funding, the funds received only cover a fraction of their costs.

Funding, in our case, was also partially complicated due to a lingering fondness for print. This attachment was sometimes based on sentimentality and/or discipline-specific preference, or driven primarily by a steady income from sales of thematic back issues. We found that the social science and humanities journals we worked with were willing to go to great lengths to preserve their print tradition by financing print runs with departmental subsidies, grant funding, and subscription revenue. In several cases, these York University-based journals did not break even after printing and mailing to subscribers, in spite of their funding from multiple sources.

This attachment to print, coupled with funding challenges, may negatively affect a journal's enthusiasm to provide timely open access to its content. We have encountered the case where a journal's attachment to print translated into a lengthy embargo of online content to ensure that subscribers in search of current issues were forced to buy print. In other cases, the journal sought an online presence mainly to present a favorable profile for future grant applications but imposed an embargo to promote the proliferation of the print version.

Finally, granting agencies themselves have not universally embraced the open access model in their grant guidelines. As a result, funding may sometimes be perceived to be contingent on print-related metrics such as number of subscribers. There are journals that would like to switch from print to exclusive online open access but are concerned that, by making that transition, conditions for funding by their granting agency may no longer be met.

While we do host a few journals that can cover their printing costs with healthy subscription revenue, sustainability on the whole remains a challenge for us as our journals navigate the ever-changing scholarly publishing landscape.

\section{Final Remarks}

It is a natural fit for libraries to support ventures that strive to make research outputs more freely available. This was, and continues to be, the objective that drives the York OJS project forward. In addition to having increased access to 
research, the library benefited by gaining firsthand experience with the publishing process and, in doing so, built expertise and understanding of the technologies that support the industry. Another advantage was an increased understanding of faculty perspectives toward publishing and open access through liaison efforts related to the project.

We noticed a marked interest in the project from the York University community, which resulted in a useful referral network that helped the project to grow. Through this network, we found that we were becoming a resource for the institutional community. Faculty, administration, and campus services increasingly associated us as partners in the research process by inviting us to meetings where scholarly publishing topics were discussed. We were invited to function as advisors and contributors to faculty research projects related to scholarly publishing topics and were included in meetings where strategies for the mobilization of institutional research outputs were discussed.

As libraries continue to support the journal format in their venture into electronic publishing, it is important to remember that their strengths lie in the technical aspects of distribution and access. ${ }^{34}$ The way in which readers are searching for journal articles is evolving. Houghton shows that users search databases by keywords and authors instead of by journal; ${ }^{35}$ so, by extension, the branding of the journal is becoming less important ${ }^{36}$ than the content of articles or the authors that publish them. Until new models of peer review are established and accepted, however, the journal format will remain a very convenient method of assembling a team of scholars in a concentrated area of study to perform editing and peer-review functions.

Our challenge in this area as libraries that host electronic journals is to ensure that our hosted content is available in a format that continues to be convenient for users to browse, search, and access. Currently, only journals that fit the Directory of Open Access Journals' restrictive definition of "open access journal" are able to take advantage of benefits of membership. These include being added to electronic resource lists and, by extension, easily imported into library catalogues worldwide. This restrictive definition excludes some of our journals that have short embargo periods but have made decades of research freely available online. While there are developments in this area, including commercial applications like Google Scholar, open source contributions like the Public Knowledge Project Open Archives Harvester and efforts on behalf of consortia such as the Synergies portal of Humanities and Social Science research, we must continue our efforts in this area to enable more comprehensive and efficient retrieval of open access resources.

\section{Notes}

1. Chawki Hajjem, Stevan Harnad, and Yves Gingras, "Ten-Year Cross-Disciplinary Comparison of the Growth of Open Access and How It Increases Research Citation Impact," IEEE Data Engineering Bulletin 28, no. 4 (2005): 39-47; Kristin Antelman, "Do Open-Access Articles Have a Greater Research Impact?" College and Research Libraries 65, no. 5 (2004): 372-82; Gunther Eysenbach, "Citation Advantage of Open Access Articles," PLoS Biology 4 no. 5 (2006), available online at doi:10.1371/journal.pbio.0040157 [Accessed 2 February 2009].

2. John Willinsky, "Open Journal Systems: An Example of Open Source Software for Journal Management and Publishing," Library Hi Tech 23 no. 4 (2005): 504-19.

3. John Willinsky, The Access Principle: The Case for Open Access to Research and Scholarship (Cambridge, Mass.: MIT Press, 2006).

4. Willinsky, "Open Journal Systems," 504.

5. Rowland Lorimer, "Online Social Science and Humanities Journal Publishing in Canada and the Synergies Project," The Serials Librarian 45, no. 2 (2003): 61-86.

6. Brian Owen and Kevin Stranack, "The Public Knowledge Project and the Simon Fraser University Library: A Partnership in Open Source and Open Access," The Serials Librarian 55 
(2008): 140-67.

7. Carol Tenopir and Donald W. King, "Trends in Scientific Scholarly Journal Publishing in the U.S.," Journal of Scholarly Publishing 28, no. 3 (1997): 135-70.

8. Lorimer, "Online Social Science and Humanities Journal Publishing," 75.

9. John M. Budd, "Serials Prices and Subscriptions in the Social Sciences, "Journal of Scholarly Publishing 33, no. 2 (2002): 90-99.

10. Mark J. McCabe, "The Impact of Publisher Mergers on Journal Prices: Theory and Evidence," The Serials Librarian 40, nos. 1-2 (2001): 157-66.

11. Julian H. Fisher, "Fixing the Broken Toaster: Scholarly Publishing Re-imagined," Science and Technology Libraries 27, no. 4 (2007): 63-76.

12. Mary M. Case and Nancy R. John, "Publishing Journals @ UIC", ARL 252/253 (June/Aug. 2007): 12-15.

13. William H. Walters, "Institutional Journal Costs in an Open Access Environment," Journal of the American Society for Information Science and Technology 58, no. 1 (2007): 108-20.

14. Chen Chi Chang, "Business Models for Open Access Journals Publishing," Online Information Review 30, no. 6 (2006): 699-713.

15. Raym Crow and Howard Goldstein, "Guide to Business Planning for Launching a New Open Access Journal," Open Society Institute Version 2, July 2003. Available online at www.soros. org/openaccess/oajguides/business_planning.pdf. [Accessed 18 August 2009].

16. Karla L. Hahn, "Research Library Publishing Service: New Options for University Publishing and New Roles for Libraries," ARL Bimonthly Report 258 (June 2008): 6-9. Available online at www.arl.org/bm doc/arl-br-258.pdf. [Accessed 2 July 2008].

17. Ibid, 6 .

18. Sarah E. Thomas, "Publishing Solutions for Contemporary Scholars: The Library as Innovator and Partner," Library Hi Tech 24, no. 4 (2006): 563-73.

19. Willinsky, The Access Principle, 212-16.

20. Peter Suber, "Open Access Overview: Focusing on Open Access to Peer-Reviewed Research Articles and Their Preprints." Available online at www.earlham.edu/ peters/fos/overview.htm. [Accessed 7 October 2008].

21. Peter Suber, SPARC Open Access Newsletter. Available online at www.earlham.edu/ peters/ fos/. [Accessed 11 January 2009].

22. David J. Solomon, Developing Open Access Journals: A Practical Guide (Oxford, England: Chandos Publishing, 2008).

23. Michael Felzczak, Rowland Lorimer, and Richard Smith, "From Production to Publishing at CJC Online: Experiences, Insights, and Considerations for Adoption," First Monday 12, no. 10 (2007). Available online at http://firstmonday.org/htbin/cgiwrap/bin/ojs/index.php/fm/article/ view/1959/1836. [Accessed 9 March 2009].

24. Owen and Stranack, "The Public Knowledge Project and the Simon Fraser University Library," 156.

25. Catherine Harboe-Ree, "Just Advanced Librarianship: The Role of Academic Libraries as Publishers," Australian Academic E Research Libraries (Mar. 2007): 15-24.

26. Helena Francke, "The State of Metadata in Open Access Journals: Possibilities and Restrictions" in Proceedings of the 12th International Conference on Electronic Publishing, Open Scholarship: Authority, Community and Sustainability in the Age of Web 2.0, ed. Leslie Chan and Susanna Mornati (Toronto: University of Toronto Press, 2008), 56-67.

27. Ibid, 58 .

28. Harboe-Ree, "Just Advanced Librarianship," 21

29. Thomas, "Publishing Solutions for Contemporary Scholars," 565.

30. Harboe-Ree, "Just Advanced Librarianship," 23.

31. Peter Suber, "Gratis and Libre Open Access," SPARC Open Access Newsletter, 124 (2008). Available online at www.earlham.edu/ peters/fos/http://www.earlham.edu/ peters/fos/newsletter/08-02-08.htm. [Accessed 5 December 2008].

32. Hahn, "Research Library Publishing Service," 8.

33. Harboe-Ree, "Just Advanced Librarianship," 23.

34. Ibid, 23.

35. John Houghton, "Economics of Publishing and the Future of Scholarly Communication" in International Yearbook of library and information management 2004/2005: Scholarly Publishing in an Electronic Era, ed. Gary Goreman and Fytton Rowland, 164-88 (London: Facet Publishing, 2004).

36. Patricia Nascimento Souto, "E-publishing Development and Changes in the Scholarly Communication System," Ciência da Informação 36, no. 1 (2007): 158-66. 